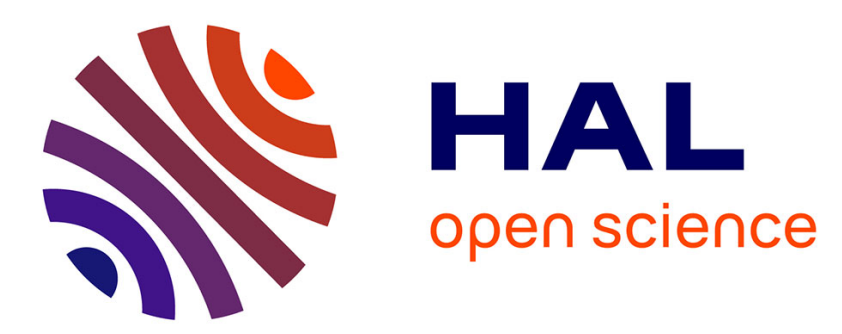

\title{
Comparison of the cellular and biochemical properties of Plasmodium falciparum choline and ethanolamine kinases
}

Blandine Alberge, Leila Gannoun-Zaki, Céline Bascunana, Christophe Tran van Ba, Henri Vial, Rachel Cerdan

\section{To cite this version:}

Blandine Alberge, Leila Gannoun-Zaki, Céline Bascunana, Christophe Tran van Ba, Henri Vial, et al.. Comparison of the cellular and biochemical properties of Plasmodium falciparum choline and ethanolamine kinases. Biochemical Journal, 2009, 425 (1), pp.149-158. 10.1042/BJ20091119 . hal00479234

\section{HAL Id: hal-00479234 \\ https://hal.science/hal-00479234}

Submitted on 30 Apr 2010

HAL is a multi-disciplinary open access archive for the deposit and dissemination of scientific research documents, whether they are published or not. The documents may come from teaching and research institutions in France or abroad, or from public or private research centers.
L'archive ouverte pluridisciplinaire HAL, est destinée au dépôt et à la diffusion de documents scientifiques de niveau recherche, publiés ou non, émanant des établissements d'enseignement et de recherche français ou étrangers, des laboratoires publics ou privés. 


\section{TITLE}

Comparison of the cellular and biochemical properties of Plasmodium falciparum choline and ethanolamine kinases.

\section{Author names}

Blandine ALBERGE* ${ }^{*}$, Leila GANNOUN-ZAKI* , Céline BASCUNANA ${ }^{\dagger}$, Christophe TRAN VAN BA*, Henri VIAL ${ }^{*}, 1$ and Rachel CERDAN ${ }^{*}, 1$

* Laboratoire de Dynamique des Interactions Membranaires Normales et Pathologiques (DIMNP) Universités de Montpellier II et I, Centre National de la Recherche Scientifique (CNRS), UMR 5235, Montpellier, F-34095, France.

$\dagger$ Present address: Laboratoire d'Ingénierie Cellulaire et Biotechnologique, CEA/DSV/IBEB/SBTN, CEA Marcoule BP 17171 Bagnols sur Cèze, F-30 207, France.

${ }^{1}$ To whom correspondence should be addressed (email rachel.cerdan@univ-montp2.fr or vial@univ-montp2.fr)

\section{Short Title:}

Choline and ethanolamine kinases of Plasmodium falciparum

\section{Key words:}

Plasmodium falciparum, choline kinase, ethanolamine kinase, phospholipid metabolism, kinetic parameter, inhibition

\section{Abbreviations used:}

PL, phospholipid; Cho, choline; ethanolamine, Etn; Ser, serine; CDP-Etn, CDP-ethanolamine; CDP-Cho, CDP-choline; PfEK, P. falciparum ethanolamine kinase; PfCK, P. falciparum choline kinase; PtdEtn, phosphatidylethanolamine; PtdCho, phosphatidylcholine; PfCEPT, $P$. falciparum choline/ethanolamine phosphotransferase; PfECT, $P$. falciparum CTP:phosphoethanolamine cytidylyltransferase; PfCCT, P. falciparum CTP:phosphocholine cytidylyltransferase; RBC, red blood cell; IRBC, infected red blood cell; NIRBC, noninfected red blood cell; HC-3, hemicholinium-3; 2-AB, 2-amino 1-butanol. 


\section{ABSTRACT}

The proliferation of the malaria-causing parasite Plasmodium falciparum within the erythrocyte is concomitant with massive phosphatidylcholine and phosphatidylethanolamine biosynthesis. Based on pharmacological and genetic data, de novo biosynthesis pathways of both phospholipids appear essential for parasite survival. The present study characterizes $P$. falciparum choline kinase (PfCK) and ethanolamine kinase $(P f \mathrm{EK})$, which catalyse the first enzymatic steps of these essential metabolic pathways. Recombinant $P f C K$ and PfEK were expressed as His-tagged fusion proteins from over-expressing E. coli strains, then purified to homogeneity and characterized. Using mice-polyclonal antibodies against recombinant kinases, $P f C K$ and $P f E K$ were shown to be localized within the parasite cytoplasm. Protein expression levels increased during erythrocytic development. PfCK and PfEK appeared specific to their respective substrate and followed Michaelis-Menten kinetics. The $\mathrm{K}_{\mathrm{m}}$ value of PfCK for choline was $135.3 \pm 15.5 \mu \mathrm{M}$. PfCK was also able to phosphorylate ethanolamine with a very low affinity. PfEK was found to be an ethanolamine-specific kinase $\left(\mathrm{K}_{\mathrm{m}}=475.7 \pm\right.$ 80.2 $\mu \mathrm{M}$ for ethanolamine). The quaternary ammonium Hemicholinium-3 and an ethanolamine analog, 2-amino 1-butanol selectively inhibited PfCK or PfEK. In contrast, the bisthiazolium compound T3 designed as a choline analog and currently in clinical trials for antimalarial treatment, affected similarly $P f C K$ and $P f E K$ activities. Inhibition exerted by T3 was competitive for both PfCK and PfEK and correlated with the impairment of cellular phosphatidylcholine biosynthesis. Comparative analyses of sequences and structures between both kinase types gave insights into their specific inhibition profiles and into the dual capacity of T3 to inhibit both PfCK and PfEK. 


\section{INTRODUCTION}

Plasmodium falciparum, the parasite of most severe forms of human malaria, requires intense membrane neogenesis to achieve successful growth and proliferation inside its hosts. During pathogenic blood development, one of the drastic changes is a six-fold increase in the content of phospholipids (PL) with a quasi-absence of cholesterol [1, 2]. Since PL salvage from the host plasma is not significant, the prodigious proliferative capacity of malaria parasite relies on its own biosynthetic machinery, more particularly on the synthesis of phosphatidylcholine (PtdCho) and phosphatidylethanolamine (PtdEtn) which represent 75 to $85 \%$ of the total parasitic PL content [3, 4]. Like other eukaryotic cells, Plasmodium is capable of synthesizing PtdCho and PtdEtn via the de novo CDP-choline and CDP-ethanolamine (Kennedy) pathways and a CDP-DAG dependent pathway leading to phosphatidylserine which can be decarboxylated into PtdEtn. In addition, a newly identified plant-like pathway involving serine decarboxylase and phosphoethanolamine $\mathrm{N}$-methyltransferase generates additional PtdCho and PtdEtn in the parasite [5-7].

Parasite-driven lipid synthesis accompanying parasite growth has been shown to be essential and many steps within PL metabolism offer potential targets for chemotherapy [8, 9]. Because the intraerythrocytic parasite relies on host-imported precursors, the use of commercial choline (Cho) or ethanolamine (Etn) analogs identified the de novo PtdCho and PtdEtn metabolic pathways as vital to the parasite blood stage [9, 10]. Unquestionably, the most advanced approach is through the use of Cho analogs possessing one or two quaternary ammoniums. Indeed, we have identified Cho analogs that inhibit $P$. falciparum asexual blood stages at single digit nanomolar concentrations [11, 12]. The bisthiazolium T3 [13] is currently in development for severe malaria in human clinical trials. The primary mechanism of T3 antimalarial activity is likely via the perturbation of an organic cation transporter that mediates Cho entry into infected erythrocytes [14], thereby preventing the first crucial step in de novo PtdCho biosynthesis [13]. The development of Cho analogs as innovative antimalaria therapeutics proves that targeting lipid metabolism is a viable approach.

An alternative pharmacological strategy consists in interfering with enzymatic steps in the essential metabolic pathways for parasite lipid formation. In the so-called Kennedy pathway, Cho diverted from the host is phosphorylated by choline kinase (CK) into phosphocholine (PCho) which is subsequently coupled to CTP, thus generating CDP-Cho by a CTPphosphocholine cytidylyltransferase (CCT). An equivalent de novo pathway exists for Plasmodium PtdEtn synthesis implying an ethanolamine kinase (EK) as first enzymatic step. In Plasmodium, the CDP-activated polar head groups are converted into the final products 
PtdCho and PtdEtn by a common parasite choline/ethanolamine phosphotransferase (CEPT) [15] in presence of diacylglycerol (supp. Figure 1). Recent genetic experiments in the rodent malaria parasite $P$. berghei indicate that the genes coding for CK, CCT, CTP: phosphoethanolamine cytidylyltransferase (ECT) and CEPT are essential for parasite survival (Déchamps and Vial, personal communication), thus identifying enzymes involved in de novo PtdCho and PtdEtn metabolic pathways as potential targets for novel antimalaria therapy.

This study aims at characterizing P. falciparum CK (PfCK) (EC 2.7.1.32) and EK (PfEK) (EC 2.7.1.82) which catalyze the first committed step for de novo PtdCho and PtdEtn synthesis, respectively, phosphorylating the plasma-originating Cho and Etn (Supp. Figure 1). In mammalian cells, CK is considered as the connection between PL metabolism and cell cycle regulation [16]. Increasing interest in CK arose from the involvement of human $\alpha$ isoform CK in cell proliferation regulation and carcinogenesis [16-18]. High levels of PtdCho resulting from an up-regulation of genes coding for Cho transporter and for CK correlate as a biochemical marker of breast cancer [19] while CK $\alpha$ depletion selectively kills many tumorderived cell lines [20-22]. Antitumoral strategy targeting this enzyme and rational drug design are currently actively investigated [23-27].

$P$. falciparum at the blood stage likely possesses two distinct proteins for the phosphorylation of Cho and Etn with specificity for their natural substrate in parasite lysates [28] and the recombinant PfCK (PlasmoDB: PF14_0020) has been characterized in vitro [29, 30]. A putative EK is annotated in the genome of all Plasmodium species (PlasmoDB: PF11_0257) (http://PlasmoDB.org) [31] but its activity has not been identified and characterized yet. This work identifies the activity of the gene product PF11_0257 as $P$. falciparum EK. A comparative study of PfCK and PfEK is presented for both their cellular expression and their properties as recombinant proteins with the characterization of their substrate requirements as well as their selective inhibition. Interestingly, we found that the bisthiazolium T3, currently developed as a choline analog for malaria therapy, equally inhibited both enzymatic activities while specifically impairing parasite PtdCho biosynthesis. 


\section{EXPERIMENTAL}

\section{Parasite culture and cDNA synthesis}

The P. falciparum 3D7 strain was maintained in A+ or $\mathrm{O}+$ human red blood cells (RBC) (Etablissement Français du Sang, Pyrénées Méditerannée) at 5\% hematocrit in RPMI 1640 medium (Gibco) supplemented with $25 \mathrm{mM}$ HEPES, $0.11 \mathrm{mM}$ hypoxanthine and $0.5 \%(\mathrm{w} / \mathrm{v})$ Albumax II (Gibco). Synchronisation of parasite cultures was performed twice at 36 hours interval using 5\% sorbitol in phosphate buffered saline (PBS) for 5 min at $37^{\circ} \mathrm{C}$ during two parasite life cycles [32]. Infected erythrocytes were lysed by $0.1 \%$ saponin in cold PBS at $4^{\circ}$ C. After centrifugation at $1300 \times \mathrm{g}$ for $5 \mathrm{~min}$, the pellet of free parasites was washed twice with cold PBS. Genomic DNA was isolated from free parasites using the QIAamp® DNA Blood Mini kit (Qiagen) according to the manufacturer's instructions. Total RNA was extracted from infected RBC (IRBC) using the RNAaqueous ${ }^{\mathrm{TM}}$ kit (Ambion) and cDNA was obtained by RT-PCR (SuperScript ${ }^{\text {TM }}$ III First-Strand Synthesis SuperMix, Invitrogen).

\section{Cloning, Over-expression and Purification of PfCK and PfEK}

The primary sequences of the full-length PfCK (440 amino-acids) and putative PfEK (423 amino-acids) were identified from PlasmoDB (http://PlasmoDB.org) [31]. The two ORFs were amplified by PCR from $P$. falciparum cDNA, using the high-fidelity Phusion polymerase with the primers 5' CAAGCTAGCATGGAAAGCAAAATCTGTGACC-3', 5'CAAGCTAGCATGGAATATCAACTAAGAGAAATTGATG-3' and the reverse primers, 5'-CAACTCGAGATCGTCATAATCCTTGATAATATTTTTG-3', 5'CAACTCGAGGTTTTTTTCCAATTTGCTCCTAAATTTTAC-3', respectively for PfCK and PfEK. Restriction sites NheI and XhoI are shown in bold. PCR fragments were ligated by T4 DNA ligase (BioLabs) into pET24b vector, to produce pET24b-PfCK and pET24b-PfEK for inducible expression of C-terminal hexahistidine-tagged recombinant proteins. All constructs were controlled by sequencing. The plasmids were transformed into E.coli strain BL21(DE3)pRIL. Bacteria were grown in LB medium containing $40 \mu \mathrm{g} / \mathrm{ml}$ chloramphenicol and $50 \mu \mathrm{g} / \mathrm{ml} \mathrm{kanamycin} \mathrm{at} 37^{\circ} \mathrm{C}$. Expression of the recombinant proteins was induced by the addition of $0.5 \mathrm{mM}$ isopropyl $\beta$-D-thiogalactopyranose (Invitrogen). Cultures were incubated for $5 \mathrm{~h}$ at $28^{\circ} \mathrm{C}$. After centrifugation $(15 \mathrm{~min}$ at $3000 \times \mathrm{g}$ ), cells were suspended in $10 \mathrm{ml}$ of lysis buffer $(25 \mathrm{mM}$ Tris-HCl, $\mathrm{pH} \quad 8.0,2 \mathrm{mM} \quad \beta$-mercapto-ethanol, $0.2 \mathrm{mM}$ phenylmethylsulfonyl fluoride) containing one protease inhibitor cocktail tablet (Complete 
Mini, EDTA-free, Roche). Lysis was performed by three passages through a French press (Thermo Spectronic), at a pressure of 1000 Pascal. Supernatants were isolated after centrifugation at $14000 \times \mathrm{g}$ for $30 \mathrm{~min}$ at $4^{\circ} \mathrm{C}$. For the first step of Plasmodium recombinant protein purification, the supernatant was loaded onto a $1 \mathrm{ml}$ HisTrap chelating column (GE Healthcare). After washing steps, the recombinant $P f C K$ and $P f E K$ were eluted with $250 \mathrm{mM}$ imidazole. Imidazole was removed on desalting PD10 column (GE Healthcare), and the NiNTA purified proteins were concentrated using Amicon Ultra-15 (Millipore) to a final volume $\sim 1 \mathrm{ml}$. The kinases were further purified on a S75 (for PfCK) or on a S200 (for PfEK) gel filtration sepharose column (HiLoad Superdex, GE Healthcare) in $0.15 \mathrm{M} \mathrm{NaCl}, 25 \mathrm{mM}$ Tris$\mathrm{HCl}, \mathrm{pH} 8.0$ buffer and $2 \mathrm{mM} \beta$-mercapto-ethanol at a flow rate of $1 \mathrm{ml} / \mathrm{min}$. Protein concentrations were determined by the Bradford method [33] with bovine serum albumin (Pierce) as standard. Purification steps were followed by SDS - polyacrylamide gel electrophoresis.

\section{Circular Dichroism analysis}

Purified recombinant proteins (concentrated at $0.3 \mathrm{mg} / \mathrm{ml}$ ) were used for UV-CD analysis in $20 \mathrm{mM}$ sodium phosphate, $\mathrm{pH} 7.4$ buffer and $2 \mathrm{mM} \beta$-mercapto-ethanol. CD spectra were recorded from 180 to $260 \mathrm{~nm}$ at $20^{\circ} \mathrm{C}$ on a Chirascan Circular Dichroism Spectrophotometer (Applied Photophysics Inc.) with a $0.5 \mathrm{~cm}$ path-length quartz cell. Data were collected at 0.5 $\mathrm{nm}$ intervals and an accumulation time of $1 \mathrm{~s}$. All protein spectra were measured three times and corrected by subtraction of respective buffer spectra. The PfCK and PfEK spectra were analysed with CDNN CD Spectra Deconvolution Software (Applied Photophysics).

\section{Antibody production and Western immunoblotting}

Eight-week-old female BALB/c mice (Charles River laboratories, France) were immunized by subcutaneous injections of 20 to $50 \mu \mathrm{g}$ of purified recombinant $P f C K$ or $P f \mathrm{EK}$ emulsified in Freund adjuvant and boosted every three weeks by two successive injections. For Western blots, IRBC were lyzed and free parasites were obtained as described in Parasite culture section. Parasite extracts were separated using 12\% SDS-PAGE under reducing conditions and transferred onto a nitrocellulose membrane (Protran, Whatman). Equivalent amount of cells were loaded in each well $\left(1 \times 10^{7}\right.$ cells/well). Membranes were incubated either with preimmune or immune mice sera (1:500 dilution for anti-PfCK and 1:2,500 dilution for anti$P f E K)$, then with horseradish peroxidase conjugated anti-mouse IgG (Promega). Signals were 
detected by chemioluminescence (ECL Western Blotting Detection Reagents, GE Healthcare).

\section{Immunofluorescence assays}

IRBC fixed in $4 \%$ para-formaldehyde and permeabilized by $0.1 \%$ Triton $\mathrm{X}-100$ for 10 min, were incubated with anti-PfCK (1:100 dilution) or anti-PfEK (1:200 dilution) antibodies overnight at $4^{\circ} \mathrm{C}$. The presence of $P f C K$ or PfEK was revealed by incubation with goat antimouse IgG green Alexa Fluor 488 (Invitrogen) for $1 \mathrm{~h}$ at room temperature. Cells were plated on 10 well-slides then mounted on slides using a Vectashield mounting medium containing diamidino phenylindole (DAPI) (Vector Laboratories, Inc.). Parasites were visualized with an upright AxioImager-Z1 microscope equipped with an apotome and differential interference contrast for transmitted light (Carl Zeiss Inc.). Images were acquired using a $\times 63,1.4$ apochromat oil-objective. Cropping and brightness/contrast adjustments were performed with Axiovision (Carl Zeiss Inc.) and ImageJ (MacBiophotonics) softwares.

\section{Kinetic parameters and inhibition assays for PfCK and PfEK}

Recombinant $P f \mathrm{CK}$ and $P f E K$ were incubated with [methyl- ${ }^{14} \mathrm{C}$ ] choline or $\left[2-{ }^{14} \mathrm{C}\right]$ ethan-1-ol2-amine with specific activity of $56 \mu \mathrm{Ci} / \mu \mathrm{mol}$ or $55 \mu \mathrm{Ci} / \mu \mathrm{mol}$, respectively (Amersham Biosciences). The enzymatic activities were measured by the formation of radio-labeled phosphocholine and phosphoethanolamine. Assays were adapted from the optimization in Plasmodium-infected homogenates [28, 34]. Enzymatic reactions were carried out with 125 mM Tris-HCl, pH 8.0 buffer, $10 \mathrm{mM}$ ATP, $5 \mathrm{mM}$ EGTA, $10 \mathrm{mM} \mathrm{MgCl}_{2}$ and $0.25 \mu \mathrm{Ci}$ of radio-labelled precursors for each assay in a final volume of $100 \mu$ l. Reactions were initiated with the addition of $0.5 \mu \mathrm{g}$ of $P f C K$ or $2 \mu \mathrm{g} P f E K$ followed by 5 or $10 \mathrm{~min}$ incubation at $37^{\circ} \mathrm{C}$ for $P f C K$ or $P f E K$, respectively. Reactions were stopped by heating at $96^{\circ} \mathrm{C}$ for $5 \mathrm{~min}$. For each assay, a sample of $20 \mu \mathrm{l}$ was spotted onto a thin layer chromatography (TLC) silica-gel plate, previously activated at $100^{\circ} \mathrm{C}$ for $1 \mathrm{~h}$. Radio-labelled products and substrates were then separated in a buffer containing ethanol/2\% ammonia $(1: 1, \mathrm{v} / \mathrm{v})$. Plates were exposed overnight to a storage phosphor screen (Molecular Biodynamics) then analyzed on a PhosphoImager (Storm 840, Amersham Biosciences). Radioactive spots identified by the migration of appropriate standards (P-Cho and P-Etn) were scraped directly into scintillation vials. Radioactivity was determined using a Beckman LS6500 liquid-scintillation spectrometer after the addition of $3 \mathrm{ml}$ of scintillant (Ultima Gold, Perkin Elmer). 
For the inhibition assays, two commercial compounds, hemicholinium-3 (Sigma), 2-amino-1butanol (Aldrich), and a bisthiazolium compound T3 were tested. Inhibition assays were performed on recombinant proteins and native $P f \mathrm{EK}$ and $P f \mathrm{CK}$ from $P$. falciparum extracts. Soluble parasite extracts were obtained after saponin treatment of synchronized IRBC cultures at the schizont stage $\left(1 \times 10^{7}\right.$ parasites $)$. Parasite pellets were washed in cold PBS and lyzed by sonication (Digital Sonifier, Branson Ultrasonics Corporation). The soluble fraction was recovered after centrifugation at $14000 \times \mathrm{g}$. Inhibition assays were measured by using the substrate concentrations at their respective affinity $\left(\mathrm{K}_{\mathrm{m}}\right.$ value) and by varying the inhibitor concentrations. For the determination of the inhibition constant $K_{i}$ of $T 3$, different concentrations of inhibitor were used. Substrate or inhibitor dependent curves were analyzed using GraphPad Prism 4 (GraphPad software, Inc.) and were represented using the MichaelisMenten equation or the Lineweaver-Burk double reciprocal plots for $\mathrm{K}_{\mathrm{m}}, \mathrm{V}_{\max }, \mathrm{K}_{\mathrm{i}}$ determination.

\section{Determination of the critical micellar concentration of T3 by light scattering}

The critical micellar concentration of T3 was determined by following the signal of dynamic light scattering when diluting a highly concentrated T3 solution. All the assays were carried out in the buffer used for the inhibition assays (Tris-HCl, $\mathrm{pH} 8$ buffer). The intensity of the Rayleigh scattering band $(R)$ (in kilo counts per second) was measured for each T3 concentration. Measurements were done on a Zeta Nano Series (Malvern Instrument) and data processed according to the manufacturer recommendations with DTS program. The intercept between the two straight lines corresponded to the cmc value.

Inhibition of P. falciparum phosphatidylcholine and phosphatidylethanolamine biosynthesis.

The incorporations of radio-labelled $\left[{ }^{3} \mathrm{H}\right]-\mathrm{Cho}(20 \mu \mathrm{M}, 0.5 \mathrm{Ci} / \mathrm{mmol})$ or $\left[{ }^{3} \mathrm{H}\right]$-Etn $(2 \mu \mathrm{M}, 4.2$ $\mathrm{Ci} / \mathrm{mmol})$ into PtdCho or PtdEtn and of $\left[{ }^{3} \mathrm{H}\right]$-hypoxanthine $(1 \mu \mathrm{Ci} /$ well $)$ into nucleic acids were measured on infected erythrocyte suspensions. Drug effects on P. falciparum growth were measured in 96 well microtiter plates filled in with $100 \mu \mathrm{l}$ of P. falciparum IRBC suspension (3\% final hematocrit and $5 \%$ parasitemia) and $50 \mu$ of complete medium (choline-free RPMI 1640, 25mM Hepes, 10\% human serum) with or without the drug. After $30 \mathrm{~min}$ incubation at $37^{\circ} \mathrm{C}, 50 \mu \mathrm{l}$ of radio-labelled precursor was added to the suspensions. Parasite cultures were maintained for 3 hours at $37^{\circ} \mathrm{C}$, and then frozen at $-80^{\circ} \mathrm{C}$. After 
thawing, the parasite macromolecules, including radioactive nucleic acids and lipids, were retained on glass fiber filters (Perkin Elmer) (pre-treated with $0.05 \%$ polyethylene glycol for Cho incorporation). Radioactivity was counted after the addition of scintillation cocktail (Ultima Gold, Perkin Elmer) in a liquid scintillation spectrometer. Dose-response curves were analyzed using GraphPad Prism 4 (GraphPad software, Inc.). The results are expressed as the concentration of drug resulting in $50 \%$ inhibition $\left(\mathrm{IC}_{50}\right)$ of Cho, Etn or hypoxanthine incorporations into PC, PE or nucleic acids, respectively.

\section{RESULTS}

\section{Sequence analysis of P. falciparum CK and putative EK}

The sequence alignment of the PfCK sequence with other known CKs exhibited three conserved motifs; (1) the ATP binding loop with the conserved residues (Ser/Thr)-Asn, (2) the Brenner's phosphotransferase motif and (3) the choline/ethanolamine kinase motif (supp. Figure 2). We focused the analysis on residues involved in the binding of the Cho or Etn moiety. The Cho/Etn kinase motif consisted in a consensus sequence described by Ayoyama et al., 2004 [35] and redefined as follows: hhDhExxxxNxxxxDhxNhhxE (h stands for large hydrophobic residue). Analysis of the X-ray 3D structures of the human and C. elegans CKs [36] and the mutational studies of C. elegans CK [37], indicated that three residues (Asp306, Gln308 and Asn311 in human CK $\alpha-2)$ belonging to the Brenner's motif were also involved in choline binding. These three residues are conserved in CK sequences including PfCK. Moreover, the choline binding site consisted of a deep hydrophobic groove and an outer negatively charged surface as described for the human CK structure in complex with the phosphocholine product [36]. The hydrophobic interactions stabilizing the quaternary amine of choline were mediated by conserved aromatic residue (Tyr333, 354, 440 and Trp420, 423 in $\mathrm{hCK} \alpha-2$ ) [36]. All five residues were found at equivalent positions in the PfCK sequence (supp. Figure 2).

The P. falciparum genome database PlasmoDB [31] predicted the presence of an intronless gene (PF11_0257) encoding a putative EK. The alignment of the putative PfEK sequence with other EKs revealed the presence of the three conserved motifs already described for CKs (supp. Figure 2). The ATP binding loop and the Brenner's motif of putative PfEK were highly similar to EK but also to CK sequences. The consensus sequence of the Cho/Etn kinase motif defined above was also present in putative PfEK. 


\section{Over-expression, purification and circular dichroism analysis of recombinant PfCK and} PfEK

We confirmed the coding sequence of $P$. falciparum EK by sequencing the cDNA of $P$. falciparum 3D7 strain (data not shown). The molecular mass of the deduced amino acid sequence was $49.9 \mathrm{kDa}$. DNA coding sequences of PfCK and PfEK were inserted into pET24b expression vector and expressed as C-terminal hexahistidine-tagged recombinant proteins in the E. coli strain BL21(DE3)pRIL. SDS-PAGE analysis of total proteins from IPTG-induced bacteria indicated the presence of prominent bands corresponding to the apparent molecular mass of approximately 50 and $48 \mathrm{kDa}$ for PfCK and PfEK, respectively (supp. Figure $3 \mathrm{~A}$ and $3 \mathrm{~B}$ ). Most of the recombinant proteins were found in the soluble fraction after bacterial lysis. Purification of each recombinant protein was performed first by a nickel-ion affinity chromatography. A further purification step using gel filtration chromatography yielded highly purified proteins as shown by the single detectable band on SDS-PAGE (supp. Figure 3C). The oligomerization states of both recombinant proteins were determined from the gel filtration elution profiles. The molecular mass obtained for PfCK on a calibrated column was $\sim 52 \mathrm{kDa}$, indicating that the protein was monomeric in $0.15 \mathrm{M} \mathrm{NaCl}$, $20 \mathrm{mM}$ Tris, $\mathrm{pH} 8$ buffer. In contrast, under the same conditions, PfEK appeared dimeric with a molecular mass of $\sim 109 \mathrm{kDa}$. Interestingly, PfCK seemed to be the only monomeric CK [29] while all other characterized CK and EK were dimeric [35, 38-40]. The dimer interface, described for human and $C$. elegans CK crystal structures, comprised 16 residues located at the C-terminal of the ATP binding loop [36, 41] (supp. Figure 2). After the two purification steps, both purified proteins were recovered at a final concentration of around $0.3 \mathrm{mg} / \mathrm{ml}$ for further studies. Average yields at the end of the purification procedure were 8-10 mg of PfEK and 1-2 mg of PfCK per litre of bacterial culture. Circular dichroism (CD) was used to assess protein folding after the purification steps. Spectra clearly exhibited two local minima and a maximum at $190 \mathrm{~nm}$ characteristic of $\alpha$-helix conformation (supp. Figure 3D). For both proteins, the $\mathrm{CD}$ spectra reflected folded proteins. Secondary structure content estimation gave approximately $30 \%$ and $40 \% \alpha$-helix for PfCK and PfEK, respectively.

\section{Cellular expression and localization of PfCK and PfEK}

We generated specific antibodies against $P f C K$ and $P f E K$ recombinant proteins by immunization of BALB-c mice. The specificity of anti-PfCK and anti-PfEK antibodies was verified by Western blot analysis of parasite extracts. Only one band was detected at the expected molecular mass for both PfCK and PfEK, while pre-immune sera did not show any 
significant signal (Figure 1A and 1B). The antibodies were then used to detect PfCK and $P f E K$ at the different stages of parasite development (ring, trophozoite and schizont stages). $P f C K$ and PfEK could not be detected by Western blot at the early stage (ring) (Figure 1C and 1D). At the trophozoite stage, anti-PfCK detected a weak band while the band detected by anti-PfEK was more intense (Figure 1C and 1D). At the end of the life cycle (schizont), both bands corresponding to $P f C K$ and $P f E K$ were more intense reflecting a maximal amount of both proteins at this stage of the P. falciparum blood development (Figure 1C and 1D). To localize both enzymes within the parasite, immunofluorescence analyses were carried out on non-synchronized parasite cultures. The signals of both anti-sera were spread throughout the parasite cytoplasm (Figure 2). Moreover, PfCK and PfEK were clearly detected at both mature stages (trophozoite and schizont) but also at the early ring stage (Figure 2), highlighting a greater sensitivity in the immunofluorescence assays with the anti-PfCK and anti-PfEK antibodies, compared to the Western blot analysis.

\section{In vitro PfCK and PfEK assays revealed two distinct enzymatic activities}

Enzymatic activities and associated kinetic parameters were determined for each purified recombinant protein. The assay conditions were adapted from the protocols optimized for extracts of P. falciparum-infected erythrocytes [28]. Enzymatic activities were measured by the formation of P-Cho or P-Etn from radio-labeled Cho or Etn, respectively. At the initial linear rate of the enzyme reactions, the activities of PfCK and PfEK were determined as substrate concentrations were increasing. The rate of catalysis described saturation curves reaching a plateau, characteristic of Michaelis-Menten kinetics for both recombinant enzyme activities (Figure 3). For PfCK, Lineweaver-Burk plot analysis of the enzyme activity with Cho yielded a $K_{m}$ value of $135.3 \pm 15.5 \mu \mathrm{M}$ and a $V_{\max }$ value of $10.7 \pm 2.8 \mu \mathrm{mol} / \mathrm{min} / \mathrm{mg}$ (Figure $3 \mathrm{~A}$ and Table 1). For PfEK, the $\mathrm{K}_{\mathrm{m}}$ value for Etn was $475.7 \pm 80.2 \mu \mathrm{M}$, revealing a weaker affinity of this kinase towards its substrate compared to PfCK (Figure 3B). The specific activity of $P f \mathrm{EK}$ for ethanolamine was determined to be $1.28 \pm 0.11 \mu \mathrm{mol} / \mathrm{min} / \mathrm{mg}$ of recombinant PfEK (Table 1). We evaluated the kinase selectivity by measuring their activities with swapped substrates. PfCK was able to catalyze the phosphorylation of Etn, but the affinity was drastically decreased and the catalytic activity was found to be $62.2 \pm 3.5$ $\mu \mathrm{mol} / \mathrm{min} / \mathrm{mg}$ (approximately 6 times higher with Etn than with Cho as substrate) (Table 1 and supp. Figure 4). In contrast, PfEK was not able to phosphorylate Cho (below a choline concentration to $1 \mathrm{M})$. PfEK was an ethanolamine-specific kinase. 


\section{Inhibition of PfCK and PfEK by selective compounds and by the antimalarial drug T3}

The chemical structures of the PfCK and PfEK substrates differ by three methyl groups. Indeed, a quaternary ammonium in Cho replaces a primary amine in Etn. Due to the substratespecificity of $P f C K$ and $P f E K$, selective inhibition of the enzymatic activities was conceivable. On the basis of chemical properties of the substrates, Hemicholinium-3 (HC-3) and 2-amino 1-butanol (2-AB) were used as Cho and Etn analogs, respectively (Figure 4A). HC-3 has been reported to be an inhibitor of choline transport [42] and CK [43-45] while 2$\mathrm{AB}$ was shown to specifically inhibit EK [28]. When added to the recombinant PfCK, HC-3 dose-dependently inhibited the kinase activity. When Cho concentration was used at its $\mathrm{K}_{\mathrm{m}}$ value, HC-3 significantly inhibited PfCK from $0.1 \mathrm{mM}$, with the concentration of drug to inhibit half of the in vitro PfCK activity (inhibition concentration $50: \mathrm{IC}_{50}$ ) of $0.58 \pm 0.02 \mathrm{mM}$ (Figure 4B). However, HC-3 was not able to significantly inhibit PfEK below an inhibitor concentration of $3 \mathrm{mM}$ (Figure 4C). Inversely, the Etn analog, 2-AB selectively inhibited PfEK activity with $\mathrm{IC}_{50}$ value of $1.36 \pm 0.17 \mathrm{mM}$ but had no significant effect on PfCK activity at this inhibitor concentration ( $\mathrm{IC}_{50}$ value above $10 \mathrm{mM}$ ) (Figure $4 \mathrm{~B}$ and $4 \mathrm{C}$ ).

The bisthiazolium T3 (Figure 4A), designed as a Cho analog to target the PtdCho synthesis pathway [13, 46], was similarly assessed on the activity of both recombinant enzymes. T3 affected the activity of $P f C K$ through an inhibition effect reflected by an $\mathrm{IC}_{50}$ value of $1.12 \pm$ $0.11 \mathrm{mM}$ (Figure 4B). Remarkably, T3 dose-dependently inhibited the PfEK activity at concentrations similar to those inhibiting PfCK as evidenced by an $\mathrm{IC}_{50}$ value of $0.61 \pm 0.02$ $\mathrm{mM}$ (Figure 4C). While the substrate analogs of CK and EK activities selectively inhibited the recombinant $P f C K$ and $P f E K$, T3 was able to equally inhibit $P f C K$ and $P f E K$ with comparable efficiency.

In addition, we investigated inhibitory properties of the compounds on $P$. falciparum endogenous $P f C K$ and PfEK activities. 2-AB and HC-3 also selectively inhibited PfEK and $P f C K$ activities, with respective $\mathrm{IC}_{50}$ of $0.46 \pm 0.03 \mathrm{mM}$ and $0.22 \pm 0.01 \mathrm{mM}$ (supp. Figure 5). The bis-thiazolium T3 inhibited both cellular activities within the same concentration range with $\mathrm{IC}_{50}$ of $0.79 \pm 0.05 \mathrm{mM}$ and $0.52 \pm 0.03 \mathrm{mM}$, respectively (supp. Figure 5). T3 similarly inhibited recombinant and endogenous kinase activities as proved by comparable $\mathrm{IC}_{50}$ values. Thus, the inhibition specificities of $2-\mathrm{AB}$ and $\mathrm{HC}-3$ and the ability of $\mathrm{T} 3$ to inhibit both kinases were found on recombinant and endogenous EK and CK activities. 
In order to elucidate the mode of action of T3, activity assays with increasing concentrations of drug were carried out on both recombinant PfCK and PfEK. Increasing concentrations of inhibitor augmented the slope of the primary plots $(1 / \mathrm{v}=\mathrm{f}(1 / \mathrm{S}))$ and all lines intersect on the $(1 / \mathrm{v})$ axis (Figure 5A and 5B). T3 acted as a competitive inhibitor of Cho and Etn substrates. The $K_{i}$ values of $T 3$, calculated from Lineweaver-Burk linearization and the plot of the apparent $\mathrm{K}_{\mathrm{m}}$ as a function of the inhibitor concentration, were found to be $1.03 \mathrm{mM}$ for PfCK and $0.73 \mathrm{mM}$ for $\mathrm{PfEK}$ (Figure $5 \mathrm{~A}$ and $5 \mathrm{~B}$ ). These values indicated that $\mathrm{T} 3$ exerts a competitive inhibitory effect with similar affinity for both $P f C K$ and $P f E K$. The Dixon plot of the reciprocal of velocity $v s$ inhibitor concentration is also a convenient way of calculating the inhibition constant. Using this graph (not shown), we found comparable $\mathrm{K}_{\mathrm{j}}$ values of T3 (0.9 and $0.7 \mathrm{mM}$ for $P f \mathrm{CK}$ and $P f \mathrm{EK}$, respectively) as those obtained from Lineweaver-Burk linearization. Taken together, these results indicated a competitive inhibition of T3 for both kinase reactions with $\mathrm{K}_{\mathrm{i}}$ values in the same range as the $\mathrm{IC}_{50}$ values and an inhibitory effect of T3 affecting $P f C K$ and $P f E K$ activities with similar affinity.

As shown in figure 4A, T3 has two positively charged head groups linked by a hydrophobic hydrocarbon chain, properties resembling those of a cationic detergent. Although, T3 exerted a competitive inhibition on $P f C K$ and $P f E K$ activities, we wanted to exclude that $\mathrm{T} 3$ could affect the proteins in a detergent like manner. Thus, we determined the critical micellar concentration $(\mathrm{cmc})$ value of T3 by dynamic light scattering. The measurements of the Rayleigh scattering band intensities $(R)$ for various T3 concentrations were performed (supp. Figure 6). For low T3 concentrations, the intensity of the scattered light followed a linear correlation resulting from the presence of monomers in the solution. As the concentration of T3 increased, the equilibrium between the monomer and the micelle forms of T3 was reached as deduced from the abrupt increase of light intensity at the $\mathrm{cmc}$. The cmc value of T3 was found to be at $200 \mathrm{mM}$ in the buffer used for inhibition assays (Tris-HCl, pH 8) (supp. Figure 6). This value was far above the $\mathrm{IC}_{50}$ values of $\mathrm{T} 3$ found to inhibit $P f C K$ and $P f E K$, excluding a detergent-like effect of the drug as the mechanism for the observed inhibition.

\section{Effects of compounds on cellular phosphatidylcholine and phosphatidylethanolamine}

\section{biosynthesis}

We monitored newly synthesized PtdCho and PtdEtn of $P$. falciparum infected erythrocytes by measuring the incorporation rate of radio-labeled precursors. $P$. falciparum cultures were treated with the three compounds $\mathrm{HC}-3, \mathrm{AB}-2$ and $\mathrm{T} 3$. To detect unspecific effects, the incorporation of radio-labeled hypoxanthine into DNA was simultaneously evaluated. The 
concentrations required to inhibit $50 \%$ of the DNA synthesis were found to be $74 \pm 5 \mu \mathrm{M}$ for T3 and above $2 \mathrm{mM}$ for HC-3 and 2-AB.

HC-3 had a complete inhibitory effect on the Cho incorporation into cellular PtdCho with an $\mathrm{IC}_{50}$ value (concentration required to inhibit $50 \%$ of PtdCho synthesis) of $79 \pm 9 \mu \mathrm{M}$ (supp. Figure 7A). At this concentration, neither PtdEtn nor the DNA synthesis were yet altered (supp. Figure 7A). The production of PtdEtn was selectively decreased by AB-2 treatment $\left(\mathrm{IC}_{50}=40 \pm 4 \mu \mathrm{M}\right)$ while this Etn analog did not affect PtdCho biosynthesis even when significantly higher concentrations were used (> $1 \mathrm{mM}$ ) (supp. Figure 7B). Thus, HC-3 and AB-2 exerted a selective effect on the de novo CDP-Cho and CDP-Etn biosynthesis pathways, respectively. When T3 was added to infected erythrocytes, the incorporation of Cho was impaired $\left(\mathrm{IC}_{50}=12 \pm 3 \mu \mathrm{M}\right)$ at concentrations that did not perturb DNA synthesis. In contrast, a decrease in PtdEtn synthesis was only observed at higher T3 concentrations that also affected hypoxanthine incorporation (supp. Figure 7C). Thus, the antimalarial effect of T3 is likely related to a decrease of parasite PtdCho but not PtdEtn synthesis.

\section{DISCUSSION}

This study provided evidence that the P. falciparum gene PF011_0257 coded for an ethanolamine kinase activity. We also showed that PfEK and PfCK were selective for their respective substrate, Etn and Cho. The catalysis of PfCK toward the phosphorylation of Etn was probably of no physiological significance since both metabolic pathways appeared essential in P. berghei parasite indicating that one enzyme cannot be substituted to the other. The levels of both kinases increased within the cytoplasm along the parasite life cycle. This suggests that $P f C K$ and PfEK could be dedicated to their own pathways, thereby increasing the possibilities for regulation processes.

As the Cho/Etn kinase motif did not exhibit any significant difference by comparing CK and EK sequences, we surmised that the specificity of these kinases resided elsewhere. Interestingly, the glutamine residue $\left(\mathrm{Q}_{290}\right.$ for PfCK and $\mathrm{Q}_{308}$ for $\left.\mathrm{hCK} \alpha-2\right)$ within the Brenner's motif, was conserved amongst the CKs while this position was occupied by a hydrophobic amino acid in EK sequences (supp. Figure 2). Ethanolamine-specific kinases lacked one of the five aromatic residues forming the hydrophobic pocket for the stabilization of the Cho quaternary amine ( $\mathrm{Y}_{329}$ for PfCK and $\mathrm{Y}_{354}$ for hCK $\left.\alpha-2\right)$ [36]. Indeed, most CKs contained an insertion encompassing the Tyr329 located at the C-terminal end of the Cho/Etn motif (supp. Figure 2), which was not found in ethanolamine-specific kinases. Thus, within 
the residues involved in the binding of the polar head substrate, CK sequences differed from EK sequences by the substitution of the pivotal polar residue of the Brenner's motif with a hydrophobic residue (Gln290 -> Leu298 for PfCK and PfEK) and by an insertion at the Cterminal of the Cho/Etn kinase motif of CKs. These observations were corroborated by the analysis of $S$. cerevisiae EK. This enzyme exhibited a polar residue (glutamine) where a hydrophobic residue is usually found (Leu298 for PfEK). Moreover, S. cerevisiae EK sequence also contained the insertion at the C-terminal of the Cho/Etn kinase motif defined above as CK specific. To our knowledge, $S c E K$ is the only EK presenting significant Cho phosphorylation activity in vitro $[16,35,39,47,48]$.

Since $P f C K$ and $P f E K$ discriminate their respective substrate containing a quaternary ammonium or a primary amine, selective inhibition by appropriate analogs is conceivable. The experiments reported here demonstrate that recombinant as well as endogenous PfCK and PfEK are selectively inhibited by two substrate analogs, HC-3 and 2-AB, respectively. Surprisingly, the antiphospholipid effector T3 designed as a Cho analog had an effect, not only on PfCK activity but also on PfEK activity. In order to obtain insights into the different inhibition profiles of $\mathrm{HC}-3$ and $2-\mathrm{AB}$ on one side and into the similar affinity of the bisthiazolium for both enzymes on the other side, we carried out a combined analysis of sequence alignments and of kinase crystal structures. As we did for the comparison of CK and EK sequences (see above and supp. Figure 2), we exploited the 3D crystal structures of PfCK and $P$. vivax EK (PfEK structure being not available) recently solved by a structural genomics consortium. Although both kinase types share the same overall fold, an interesting difference appeared when both structures were superimposed. Indeed, the PfCK crystal structure showed that the insertion comprising the tyrosine residue at the C-terminal of the Cho/Etn kinase motif was located near the catalytic site (Figure 6). As was evident in the primary sequence alignment, this insertion was absent in EK sequences. Additionally, the human CK crystal structure in complex with HC-3 revealed that one aromatic ring of HC-3 stacked onto the tyrosine ring residue of the insertion $\left(\mathrm{Y}_{354}\right.$ for $\left.\mathrm{hCK} \alpha-2\right)$ (Figure 6). This CK-specific interaction could be indispensable to discriminate between the inhibitors and thus the substrates, whereas the absence of the insertion in PfEK preventing any Tyr-mediated interaction would be detrimental for HC-3 or Cho binding. Similar affinities of T3 for both enzymes were observed. It is likely that the conformation of the thiazolium head group being planar contrary to Cho and HC-3 quarternary ammonium, allows its entry into the PfEK catalytic site. Additionally, the flexibility due to the 12-carbon atom linker between both 
thiazolium groups, could allow quaternary ammonia (or just one ammonium) to adapt to $P f C K$ and PfEK catalytic sites.

More investigations are needed to explain the dual potentiality of T3 on both $P f C K$ and $P f E K$ activities. Since both metabolic pathways are essential, $P f C K$ and $P f E K$ appear crucial for the $P$. falciparum survival. In the parasite, T3 selectively impaired PtdCho biosynthesis that likely explains its antimalarial effect while PtdEtn biosynthesis did not appear to be primarily affected. As mentioned above, the primary action of T3 is likely to prevent Cho entry into the parasites by blocking an organic cation transporter. Nevertheless, the inhibition of two Plasmodium enzymes at similar levels opens the way to the design of new scaffolds toward dual molecules. The ability to affect more than one target for antimalarial therapy is precious to delay the emergence of resistant malaria strains, which is currently a crucial issue in the battle against malaria. 3D crystal structures of complexes between these both enzymes and T3 should provide the atomic details of the interactions, necessary for future structure-based drug design of novel analogs.

\section{ACKNOWLEDGEMENTS:}

We thank Dr. Martin Cohen-Gonsaud at the Centre de Biochimie Structurale in Montpellier for helpful discussions and help with circular dichroism experiments. We are grateful to Dr. Kai Wengelnik for helpful discussions and critical reading of this manuscript.

The P. falciparum 3D7 strain was obtained through the Malaria Research and Reference Reagent Resource Center (MR4).

\section{FUNDING:}

This work was supported by the European Union FP6 Network of Excellence BioMalPar LSHP-CT-2004-503578 and Integrated project Antimal [N IP-018834]. 


\section{REFERENCES:}

1 Vial, H. and Ancelin, M. L. (1992) Malarial Lipids An overview. In Subcellular Biochemistry (Press, P., ed.), pp. 259-306, Avila, J. L. Harris, J. R., New York

2 Vial, H. J., Eldin, P., Tielens, A. G. M. and van Hellemond, J. J. (2003) Phospholipids in parasitic protozoa. Mol. Biochem. Parasitol. 126, 143-154

3 Holz, G. G. (1977) Lipids and the malaria parasite. Bull. Wld. Hlth. Organiz (WHO) 55, $237-248$

4 Vial, H. and Ben Mamoun, C. (2005) Plasmodium Lipids: Metabolism and Function In Molecular Approach to Malaria. In Plasmodium Lipids: Metabolism and Function In Molecular Approach to Malaria (Sherman, I. W., ed.), pp. 327-352, ASM Press, Washington, DC

5 Elabbadi, N., Ancelin, M. L. and Vial, H. J. (1997) Phospholipid metabolism of serine in Plasmodium-infected erythrocytes involves phosphatidylserine and direct serine decarboxylation. Biochem. J. 324, 435-445

6 Pessi, G., Choi, J. Y., Reynolds, J. M., Voelker, D. R. and Mamoun, C. B. (2005) In vivo evidence for the specificity of Plasmodium falciparum phosphoethanolamine methyltransferase and its coupling to the Kennedy pathway. J Biol Chem 280, 1246112466

7 Pessi, G., Kociubinski, G. and Ben Mamoun, C. (2004) A pathway for phosphatidylcholine biosynthesis in Plasmodium falciparum involving phosphoethanolamine methylation. Proceedings of the National Academy of Sciences of the United States of America 101, 6206-6211

8 Salom-Roig, X. J., Hamzé, A., Calas, M. and Vial, H. J. (2005) Dual molecules as new antimalarials. Com. Chem. High T. Scr. 8, 47-60

9 Vial, H. and Calas, M. (2000) Inhibitors of Phospholipid Metabolism. In Antimalarial Chemotherapy, mechanims of action, modes of resistance, and new directions in drug development (P., R., ed.), pp. 347-365, The Humana Press Inc

10 Vial, H. J. Thuet, M. J., Ancelin, M. L., Philippot, J. R. and Chavis, C. (1984) Phospholipid-Metabolism as a New Target for Malaria Chemotherapy - Mechanism of Action of D-2-Amino-1-Butanol. Biochem. Pharmacol. 33, 2761-2770

11 Calas, M., Ancelin, M. L., Cordina, G., Portefaix, P., Piquet, G., Vidal-Sailhan, V. and Vial, H. (2000) Antimalarial activity of compounds interfering with Plasmodium falciparum phospholipid metabolism: Comparison between mono- and bisquaternary ammonium salts. J. Med. Chem. 43, 505-516 
12 Ancelin, M. L., Calas, M., Bonhoure, A., Herbute, S. and Vial, H. J. (2003) In vivo antimalarial activities of mono- and bis quaternary ammonium salts interfering with Plasmodium phospholipid metabolism. Antimicrobial Agents and Chemotherapy 47, 2598-2605

13 Vial, H. J., Wein, S., Farenc, C., Kocken, C., Nicolas, O., Ancelin, M. L., Bressolle, F., Thomas, A. and Calas, M. (2004) Prodrugs of bisthiazolium salts are orally potent antimalarials. Proc. Natl Acad Sci USA 101, 15458-15463

14 Biagini, G. A., Pasini, E., Hughes, R., De Koning, H. P., Vial, H., O'Neill, P., Ward, S. and Bray, P. (2004) Characterization of the choline carrier of Plasmodium falciparum: a route for the selective delivery of novel antimalarial drugs. Blood Cells 104

15 Vial, H. J., Thuet, M. J. and Philippot, J. R. (1984) Cholinephosphotransferase and Ethanolaminephosphotransferase Activities in Plasmodium-Knowlesi-Infected Erythrocytes - Their Use as Parasite-Specific Markers. Biochimica Et Biophysica Acta 795, 372-383

16 Ramirez de Molina, A., Gallego-Ortega, D., Sarmentero-Estrada, J., Lagares, D., Gomez del Pulgar, T., Bandres, E., Garcia-Fontillas, J. and Lacal, J. C. (2008) Choline kinase as a link connecting phospholipid metabolism and cell cycle regulation: Implications in cancer therapy. The International Journal of Biochemistry \& Cell Biology 40, 1753-1763

17 Glunde, K., Jie, C. and Bhujwalla, Z. M. (2004) Molecular causes of the aberrant choline phospholipid metabolism in breast cancer. Cancer Research 64, 4270-4276

18 Cui, Z. and Houweling, M. (2002) Phosphatidylcholine and cell death. Biochimica Et Biophysica Acta-Molecular and Cell Biology of Lipids 1585, 87-96

19 Eliyahu, G., Kreizman, T. and Degani, H. (2007) Phosphocholine as a biomarker of breast cancer: Molecular and biochemical studies. International Journal of Cancer 120, 1721-1730

20 Rodriguez-Gonzalez, A., de Molina, A. R., Fernandez, F., Ramos, M. A., Nunez, M. D., Campos, J. and Lacal, J. C. (2003) Inhibition of choline kinase as a specific cytotoxic strategy in oncogene-transformed cells. Oncogene 22, 8803-8812

21 Rodriguez-Gonzales, A., de Molina, A. R., Fernandez, F. and Lacal, J. C. (2004) Choline kinase inhibition induces the increase in ceramides resulting in a highly specific and selectives cytotoxic antitumoral strategy as a potential mechanism of action. Oncogene 23, 8247-8259 
22 Banez-Coronel, M., de Molina, A. R., Rodriguez-Gonzalez, A., Sarmentero, J., Ramos, M. A., Garcia-Cabezas, M. A., Garcia-Oroz, L. and Lacal, J. C. (2008) Choline Kinase Alpha Depletion Selectively Kills Tumoral Cells. Current Cancer Drug Targets 8, 709-719

23 Milanese, L., Espinosa, A., Campos, J. M., Gallo, M. A. and Entrena, A. (2006) Insight into the inhibition of human choline kinase: Homology modeling and molecular dynamics simulations. Chemmedchem 1, 1216-1228

24 Campos, J., Nunez, M. D., Rodriguez, V., Gallo, M. A. and Espinosa, A. (2000) QSAR of 1,1 '(1,2-ethylenebisbenzyl)bis(4-substitutedpyridinium) dibromides as choline kinase inhibitors: a different approach for antiproliferative drug design. Bioorganic \& Medicinal Chemistry Letters 10, 767-770

25 Campos, J., Nunez, M. C., Conejo-Garcia, A., Sanchez-Martin, R. M., HernandezAlcoceba, R., Rodriguez-Gonzalez, A., Lacal, J. C., Gallo, M. A. and Espinosa, A. (2003) QSAR-derived Choline Kinase inhibitors: How rational can antiproliferative drug design be? Current Medicinal Chemistry 10, 1095-1112

26 Janardhan, S., Srivani, P. and Sastry, G. N. (2006) 2D and 3D quantitative structureactivity relationship studies on a series of bis-pyridinium compounds as choline kinase inhibitors. Qsar \& Combinatorial Science 25, 860-872

27 Nunez, M. C., Conejo-Garcia, A., Sanchez-Martin, R. M., Gallo, M. A., Espinosa, A. and Campos, J. M. (2007) QSAR as a tool for the development of potent antiproliferative agents by inhibition of choline kinase. Current Computer-Aided Drug Design 3, 297-312

28 Ancelin, M. L. and Vial, H. J. (1986) Several Lines of Evidence Demonstrating That Plasmodium-Falciparum, a Parasitic Organism, Has Distinct Enzymes for the Phosphorylation of Choline and Ethanolamine. Febs Letters 202, 217-223

Choubey, V., Guha, M., Maity, P., Kumar, S., Raghunandan, R., Maulik, P. R., Mitra, K., Halder, U. C. and Bandyopadhyay, U. (2006) Molecular characterization and localization of Plasmodium falciparum choline kinase. Biochimica et Biophysica Acta 1760, $1027-1038$

30 Choubey, V., Maity, P., Guha, M., Kumar, S., Srivastava, K., Kumar Puri, S. and Bandyopadhyay, U. (2007) Inhibition of Plasmodium falciparum Choline Kinase by Hexadecyltrimethylammonium Bromide: a Possible Antimalarial Mechanism. Antimicrob. Agents Ch. 51, 696-706 
31 Aurrecoechea, C., Brestelli, J., Brunk, B. P., Dommer, J., Fischer, S., Gajria, B., Gao, X., Gingle, A., Grant, G., Harb, O. S., Heiges, M., Innamorato, F., Iodice, J., Kissinger, J. C., Kraemer, E., Li, W., Miller, J. A., Nayak, V., Pennington, C., Pinney, D. F., Roos, D. S., Ross, C., Stoeckert, C. J., Treatman, C. and Wang, H. M. (2009) PlasmoDB: a functional genomic database for malaria parasites. Nucleic Acids Research 37, D539-D543

32 Lambros, C. and Vanderberg, J. P. (1979) Synchronization of Plasmodium-Falciparum Erythrocytic Stages in Culture. Journal of Parasitology 65, 418-420

33 Bradford, M. M. (1976) A rapid and sensitive method for the quantitation of microgram quantities of protein utilizing the principle of proteindye binding. Anal.Biochem. 72, 248-254

34 Ancelin, M. L. and Vial, H. J. (1986) Choline Kinase-Activity in Plasmodium-Infected Erythrocytes - Characterization and Utilization as a Parasite-Specific Marker in Malarial Fractionation Studies. Biochimica Et Biophysica Acta 875, 52-58

35 Aoyama, C., Liao, H. and Ishidate, K. (2004) Structure and function of choline kinase isoforms in mammalian cells. Progress in Lipid Research 43, 266-281

36 Malito, E., Sekulic, N., Cun See Too, W., Konrad, M. and Lavie, A. (2006) Elucidation of Human Choline Kinase Crystal Structures in Complex with the Products ADP or Phosphocholine. Journal of Molecular Biology 364, 136-151

37 Yuan, C. and Kent, C. (2004) Identification of critical residues of choline kinase A2 from Caenorhabditis elegans. Journal of Biological Chemistry 279, 17801-17809

38 Gee, P. and Kent, C. (2003) Multiple isoforms of choline kinase from Caenorhabditis elegans: cloning, expression, purification, and characterization. Biochimica Et Biophysica Acta-Proteins and Proteomics 1648, 33-42

39 Gibellini, F., Hunter, W. N. and Smith, T. K. (2008) Biochemical characterization of the initial steps of the Kennedy pathway in Trypanosoma brucei: the ethanolamine and choline kinases. Biochemical Journal 415, 135-144

40 Kim, K. H., Voelker, D. R., Flocco, M. T. and Carman, G. M. (1998) Expression, purification, and characterization of choline kinase, product of the CKI gene from Saccharomyces cerevisiae. Journal of Biological Chemistry 273, 6844-6852

41 Peisach, D., Gee, P., Kent, C. and Xu, Z. (2003) The Crystal Structure of Choline Kinase Reveals a Eukaryotic Protein Kinase Fold. Structure 11, 703-713 
42 Zlatkine, P., Moll, G., Blais, A., Loiseau, A. and Legrimellec, C. (1993) Transport of Choline by Madin-Darby Canine Kidney-Cells. Biochimica Et Biophysica Acta 1153, 237-242

43 Hamza, M., Lloveras, J., Ribbes, G., Soula, G. and Dousteblazy, L. (1983) An Invitro Study of Hemicholinium-3 on Phospholipid-Metabolism of Krebs-Ii Ascites-Cells. Biochemical Pharmacology 32, 1893-1897

44 Cuadrado, A., Carnero, A., Dolfi, F., Jimenez, B. and Lacal, J. C. (1993) Phosphorylcholine - a Novel 2nd Messenger Essential for Mitogenic Activity of Growth-Factors. Oncogene 8, 2959-2968

45 Lacal, J. C. (2001) Choline kinase: a novel target for antitumor drugs. IDrugs 4, 419426

46 Hamze, A., Rubi, E., Arnal, P., Boisbrun, M., Carcel, C., Salom-Roig, X., Maynadier, M., Wein, S., Vial, H. and Calas, M. (2005) Mono- and bis-thiazolium salts have potent antimalarial activity. Journal of Medicinal Chemistry 48, 3639-3643

47 Kim, K. S., Kim, K. H., Storey, M. K., Voelker, D. R. and Carman, G. M. (1999) Isolation and characterization of the Saccharomyces cerevisiae EKI1 gene encoding ethanolamine kinase. Journal of Biological Chemistry 274, 14857-14866

48 Lykidis, A., Wang, J., Karim, M. A. and Jackowski, S. (2001) Overexpression of a mammalian ethanolamine-specific kinase accelerates the CDP-ethanolamine pathway. Journal of Biological Chemistry 276, 2174-2179 


\section{TABLE:}

Table 1: Kinetic values for recombinant $P f C K$ and $P f E K$.

\begin{tabular}{|c|c|c|}
\hline Enzyme & $\mathrm{K}_{\mathrm{m}}(\mu \mathrm{M})$ & $\mathrm{V}_{\max }(\mu \mathrm{mol} / \mathrm{min} / \mathrm{mg})$ \\
\hline \multicolumn{3}{|l|}{ PfCK } \\
\hline choline & $135.3 \pm 15.5$ & \\
\hline ethanolamine & $>500 \mathrm{mM}$ & \\
\hline \multicolumn{3}{|l|}{ PfEK } \\
\hline ethanolamine & $457.7 \pm 80.2$ & \\
\hline choline & NA & NA \\
\hline
\end{tabular}

NA for non applicable 


\section{FIGURE LEGENDS:}

\section{Figure 1: Western immunoblot of $P f C K$ and $P f E K$}

Western blots were revealed with anti-PfCK $(\mathrm{A}, \mathrm{C})$ and anti-PfEK $(\mathrm{B}, \mathrm{D})$. For A and B: Lane 1, immune serum on non-infected erythrocytes; Lane 2, immune serum on $P$. falciparum lysate; Lane 3, pre-immune serum on P. falciparum lysate.

For $\mathrm{C}$ and $\mathrm{D}$ panels, Western blots were revealed at the three parasite stage development (R: ring; T, trophozoite; S: schizont). Parasite cultures were synchronized and an equal quantity of parasites $\left(10^{7}\right.$ cells $)$ was treated for each stages.

\section{Figure 2: PfCK and PfEK localization}

Immunofluorescence assays were done on human red blood cells infected by $P$. falciparum 3D7 strain and revealed by anti-PfCK (A) or anti-PfEK (B) (green). Nuclei were stained in blue with DAPI. Differential interference contrast (DIC) images and merges were presented. Three representative parasitic stages were shown: ring, mature trophozoite and schizont.

\section{Figure 3: Kinetic parameters of $P f \mathrm{CK}$ and $P f \mathrm{EK}$}

Activity was measured by the formation of phosphocholine or phosphoethanolamine with increasing substrate concentrations (see Experimental section). Experiments have been done four times for $P f C K$ and three times for $P f E K$, each time in duplicate. Representative Michaelis-Menten and Lineweaver-Burk linearization (inserts) plots are shown for PfCK (A), and PfEK (B) enzymes. Activity was expressed as $\mu \mathrm{mol} / \mathrm{min} / \mathrm{mg}$. Data were presented as mean \pm standard deviation from three measurements.

\section{Figure 4: Inhibition of recombinant $P f C K$ and $P f E K$}

(A) Chemical structures of two commercial compounds, Hemicholinium-3 and 2-amino-1 butanol known to inhibit CK and EK, respectively and of T3 which belongs to the second generation of bis-quaternary ammonium salt. The chemical structure of T3 is a duplicated bisthiazolium separated by a 12-carbon atom aliphatic chain. This compound is currently under human clinical trials. $(\mathrm{B}, \mathrm{C})$ Inhibition curves of $P f \mathrm{CK}$ and $P f \mathrm{EK}$. Activities of $P f \mathrm{CK}(\mathrm{B})$ and $P f E K(C)$ were measured with increasing concentrations of both specific inhibitors $\mathrm{HC}-3(\Delta)$, 2-AB(०) and of T3 ( $)$. Activity of both enzymes was giving in percentage of controls. Data are presented as mean \pm standard deviation from three measurements. The inhibitor concentrations at $50 \%$ activity corresponded to the $\mathrm{IC}_{50}$ values (dotted lines). 


\section{Figure 5: Inhibition kinetic of $P f C K$ (A) and $P f E K$ (B) by T3 compound}

On the left panels, Lineweaver-Burk plots were shown at increasing drug concentrations ; (A) inhibition of $P f C K$ with $0(\Delta), 0.5(\circ)$ and $1 \mathrm{mM}(\boldsymbol{\Delta})$ T3 ; (B) inhibition of PfEK $0(\Delta), 0.25$ ( $\square$ ) and $0.5(\circ) \mathrm{mM} \mathrm{T3}$. Experiments were done twice in triplicate. Data are presented as mean \pm standard deviation from three measurements.

On the right panels, (A) for $P f C K$ and (B) for PfEK, the apparent $\mathrm{K}_{\mathrm{m}}\left(\mathrm{K}_{\mathrm{m}}{ }^{\prime}\right)$ were plotted as function of the inhibitor concentration, $K_{i}$ values were obtained by the value at the intercept with the $\mathrm{x}$-axis as indicated by the arrow (-Ki).

\section{Figure 6: Comparison of $P f C K$ and $P$. vivax EK crystal structures}

Superimposition of the Brenner's and Cho/Etn kinase motifs of PfCK (black) and $P$. vivax EK (grey) crystal structures. The insertion containing the tyrosine 329 is not present in $P v \mathrm{EK}$ structure. Side-chains of Gln290 (PfCK) and Leu298 ( $P v$ EK) residues conserved amongst CK and EK, respectively, are indicated. The position of $\mathrm{HC}-3$ (white) was obtained by the superimposition of the hCK $\alpha-2$ structure in complex with HC-3. Only HC-3 was let visible. The model suggested that the tyrosine 329 of PfCK (equivalent to Tyr354 in hCK $\alpha-2$ ) could interact with HC-3 aromatic ring. The PDB files used were $3 \mathrm{FI} 8$ for $P f \mathrm{CK}, 2 \mathrm{QG} 7$ for $P v \mathrm{EK}$ and 3FI2 for the hCK $\alpha-2-$ HC-3 complex. This figure has been done with PyMol software. 
Figure 1

A

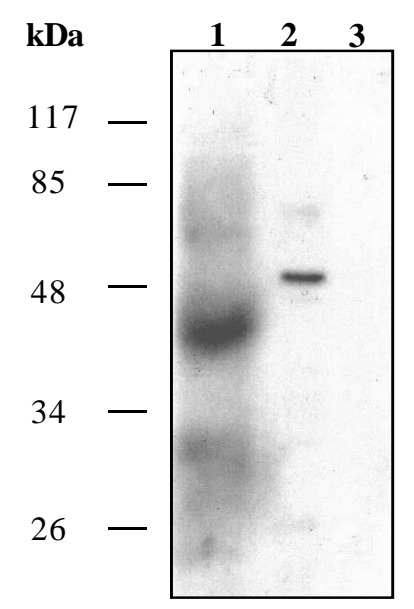

$\mathbf{C}$

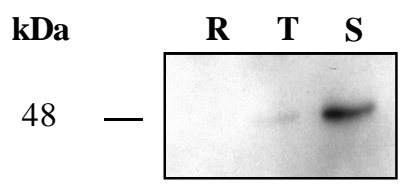

B

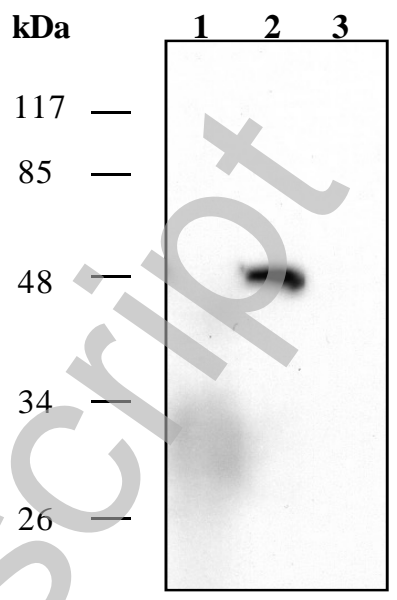

D

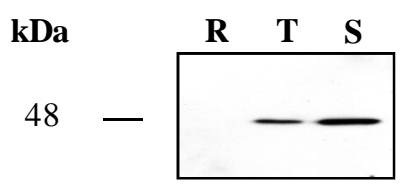


B Biochemical Journal Immediate Publication. Published on 21 Oct 2009 as manuscript BJ20091119

Figure 2

A

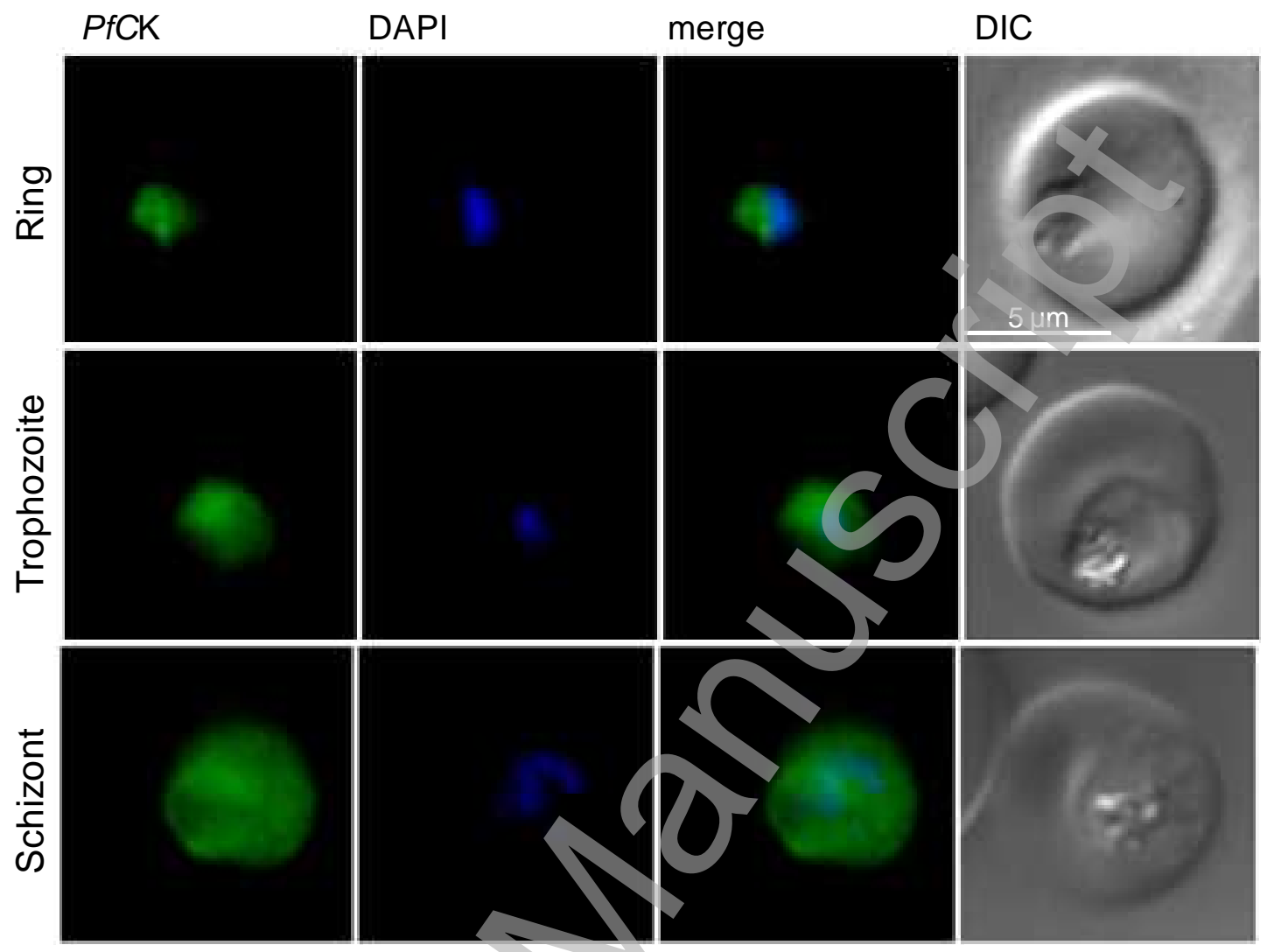

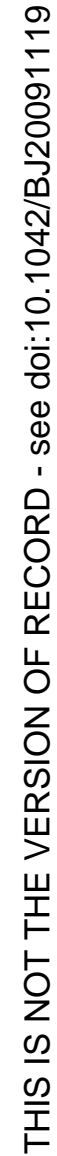


B Biochemical Journal Immediate Publication. Published on 21 Oct 2009 as manuscript BJ20091119

Figure 2

B

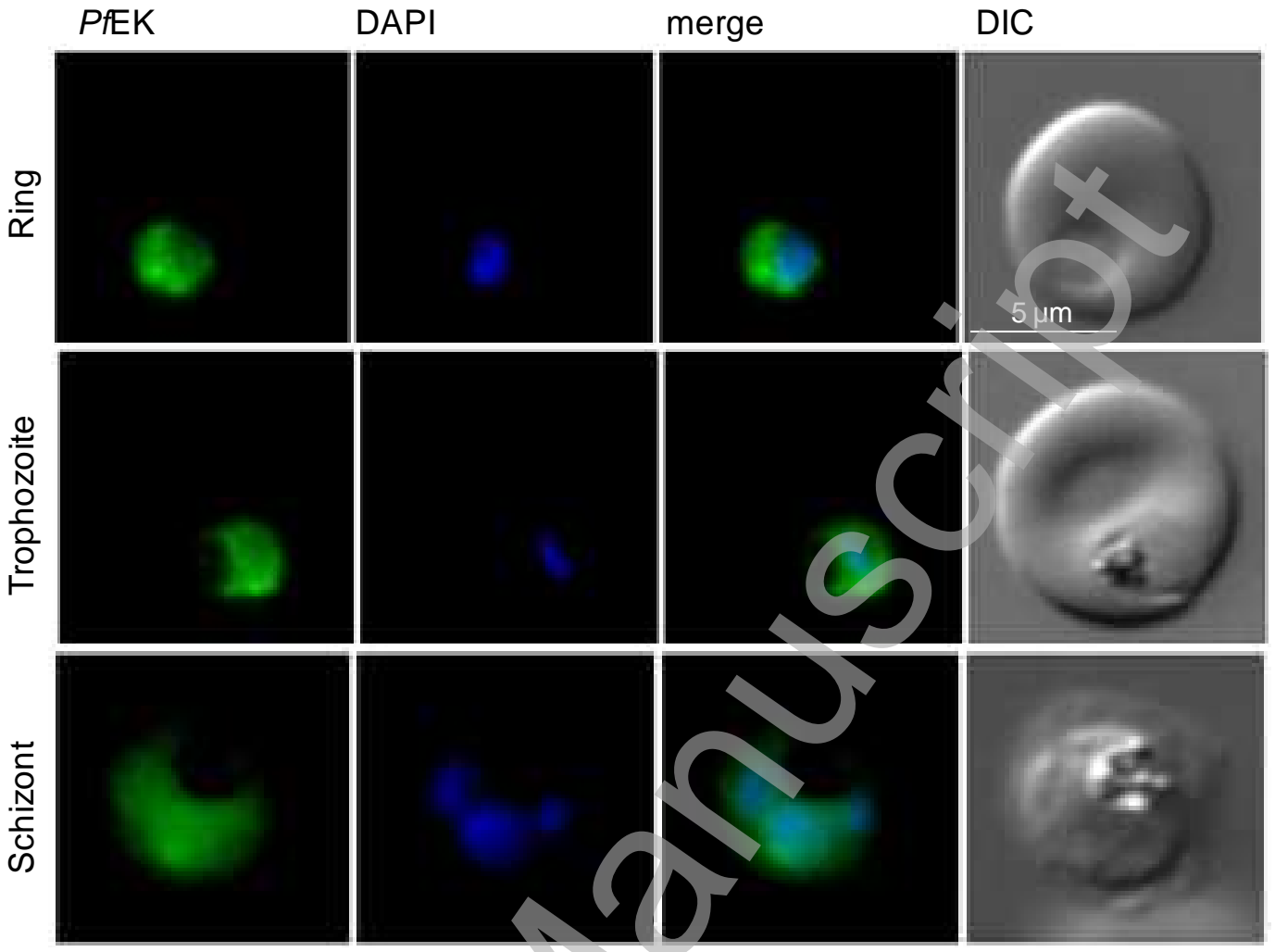

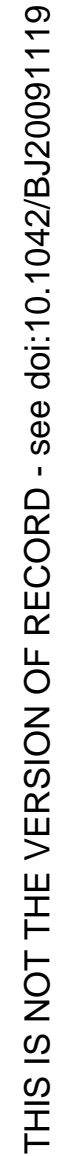


Figure 3

A

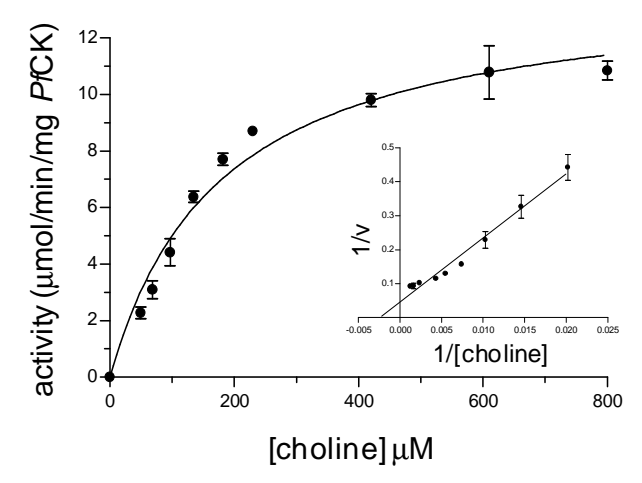

B

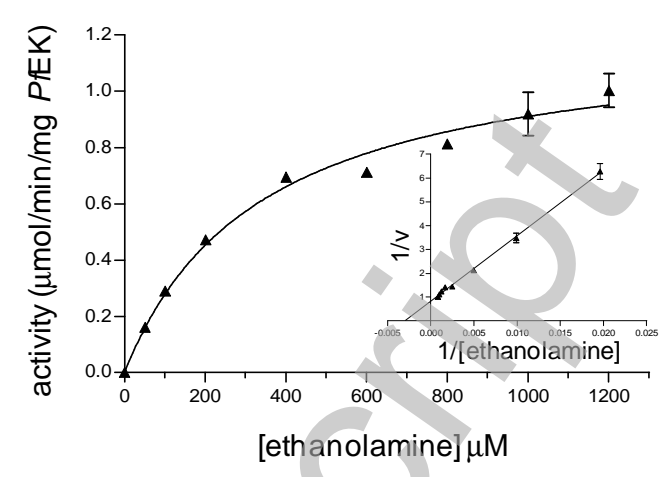


Figure 4

A

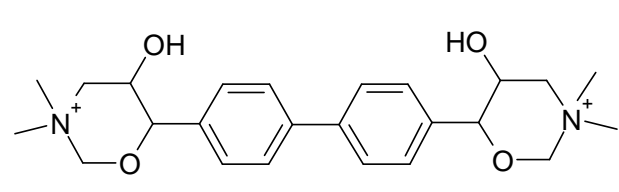

Hemicholinium-3<smiles>CCC(N)CO</smiles>

2-amino-1 butanol

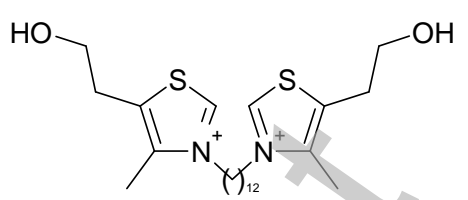

T3 (SAR 97276)
B

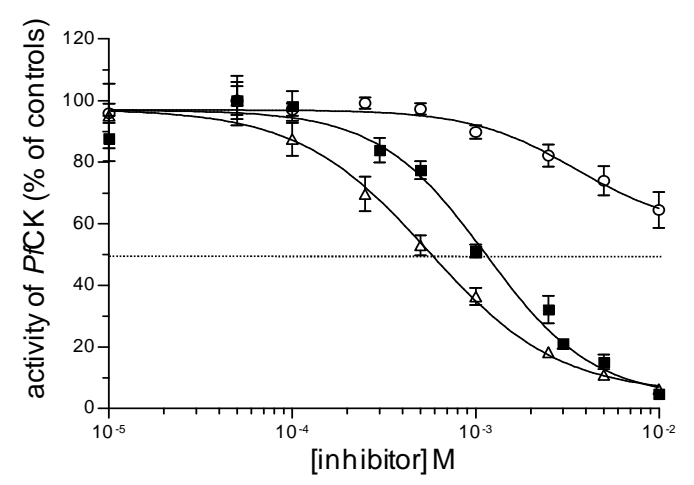

C

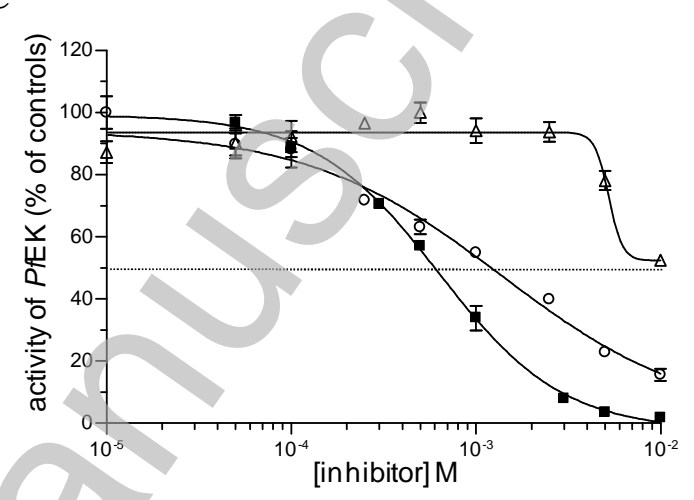

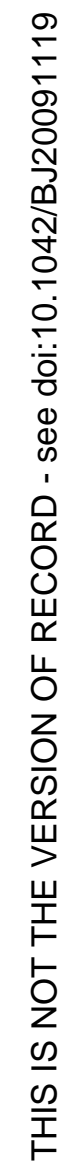


Figure 5

A

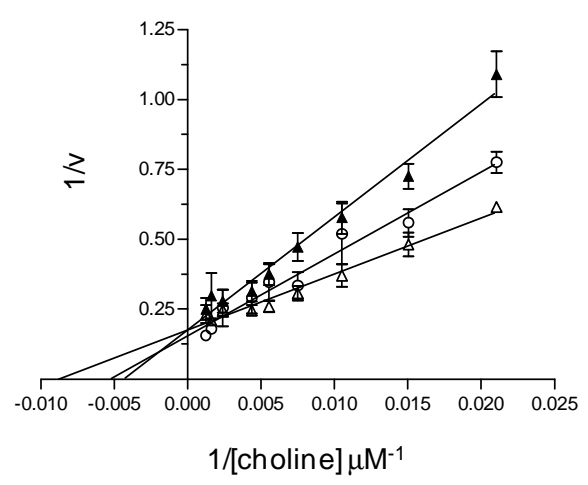

B

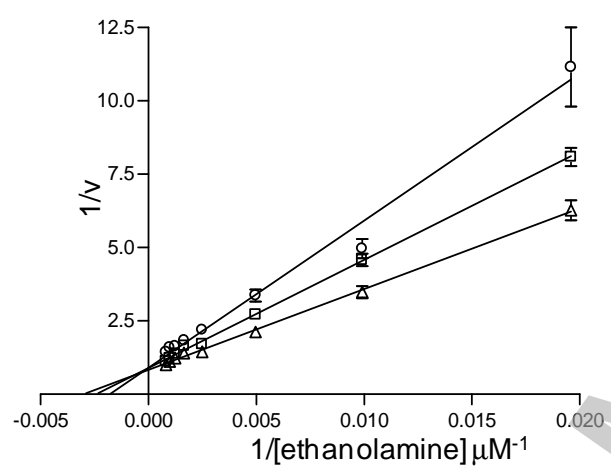

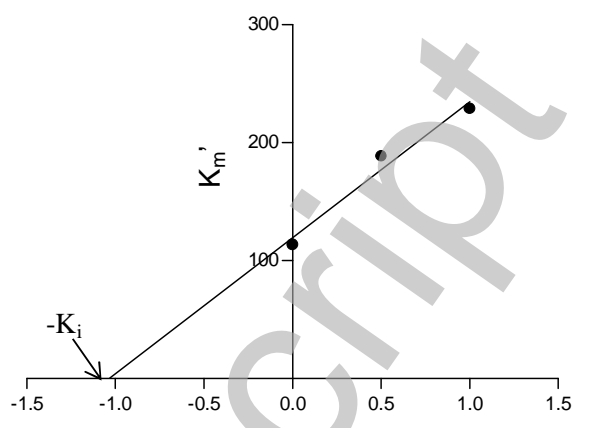

[13] $\mathrm{mM}$

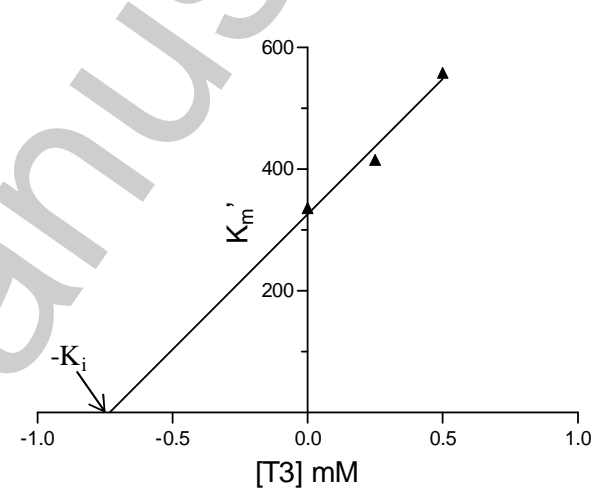

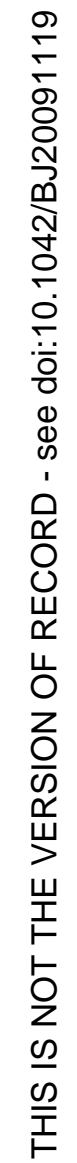


Figure 6

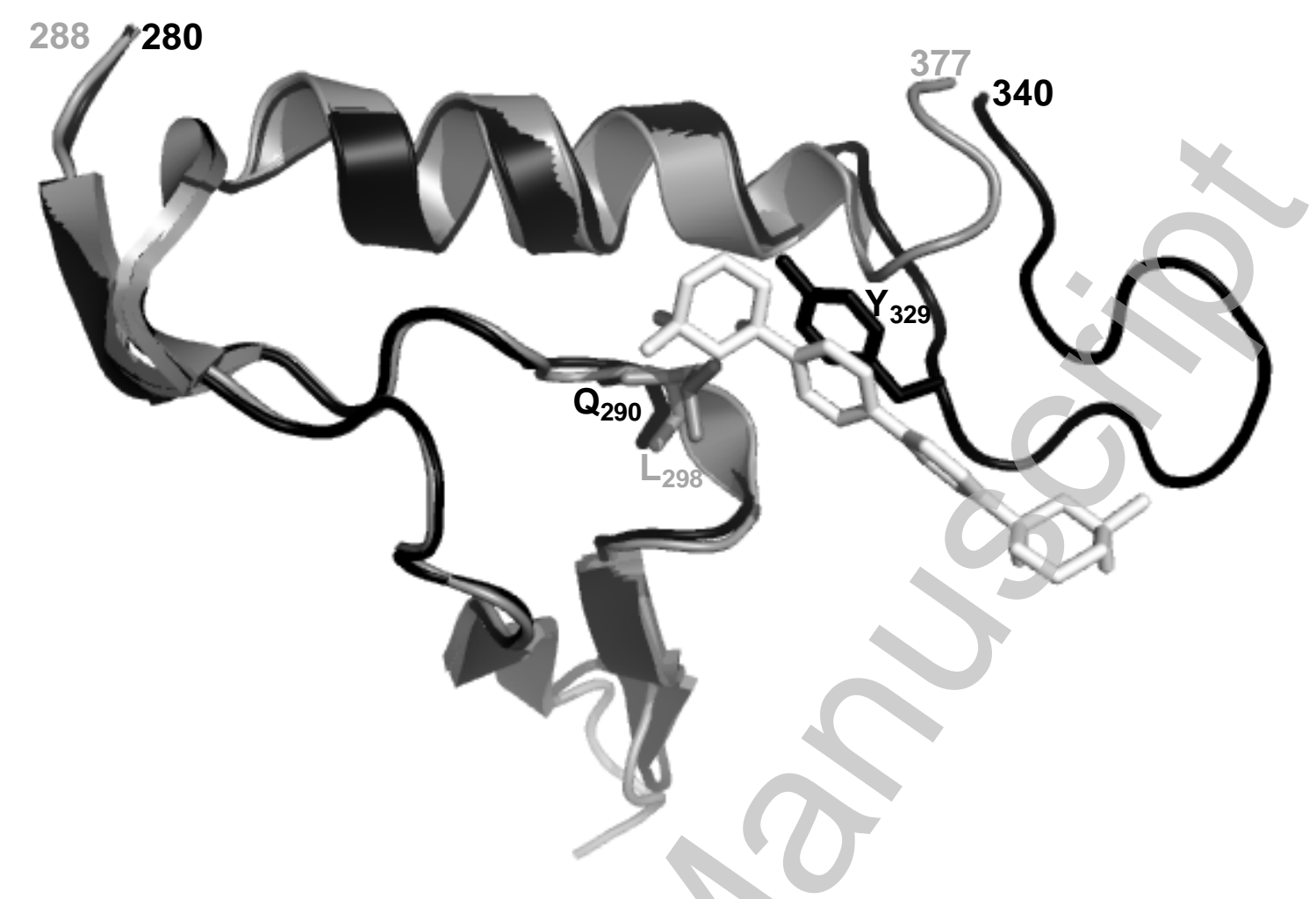

